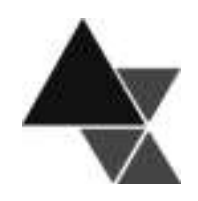

\title{
CRESCIMENTO DA ALIMENTAÇÃO FORA DO DOMICÍLIO
}

\author{
Daniele Leal $^{1}$
}

Em decorrência das intensas mudanças nas últimas décadas, notadamente no estilo de vida da população, ocorreu o aumento significativo da alimentação fora do domicílio. Alguns fatores influenciaram este fato, como ampliação dos serviços dos restaurantes (fast food, self service, "prato feito"), proporção da despesa destinada à alimentação, envolvimento com programa de alimentação institucional, como é o caso do programa de alimentação do trabalhador, alimentação escolar, crescimento do segmento de serviços de alimentação, entre outros. O objetivo desta revisão é discutir os condicionantes do crescimento da alimentação fora do domicílio.

Palavras-chave: serviço de alimentação, segurança alimentar e segurança nutricional.

\section{GROWTH OF FEEDING AWAY FROM}

Due to the many changes happening in the last decades, notably in lifestyle, a significant increase in food consumption away from the domicile has occurred. Some factors appear to have influenced such a fact, like food services (fast food, self-service restaurants), portion of the family budget allotted to meals by the population, institutional food programs (worker's food program, school meals, among others) and an expanding food service network. This review is aimed at discussing the increasing frequency with which meals are taken away from home and its conditionants.

Key words: food services, food safety, food security.

\section{Introdução}

Com a intensa urbanização e industrialização, ocorridas durante os anos 1950 e 1960, crescente profissionalização das mulheres, elevação do nível de vida e de educação, generalização do uso do carro, maior acesso da população ao lazer (férias) e viagens, foi alterada a gestão de tempo aplicado à alimentação. Nesta busca pelo ganho de tempo aumenta o número de refeições feitas fora de casa. Intensifica-se também o consumo de refeições servidas em escolas públicas, cantinas de unidades de ensino (redes pública e privada) e empresas [1,2].

No que tange as mudanças relacionadas ao mercado de trabalho, de acordo com dados publicados pela Fundação Carlos Chagas [3], entre 1976 e 2002, houve um acréscimo de 25 milhões de trabalhadoras no mercado de trabalho. As mulheres passaram a desempenhar um papel muito mais relevante do que os homens no crescimento da população economicamente ativa. No ano de 1976, 28,8\% das mulheres eram economicamente ativas, representando $30,3 \%$ entre os empregados e em 2002, a proporção alcançava 42,5\%, representando $35,8 \%$ entre os empregados [3].

Nos últimos 25 anos as mulheres alcançaram um maior nível de escolaridade se comparadas com os homens e a associação entre a escolaridade e a participação das mulheres não empregadas é forte. Em 2002, por exemplo, $31 \%$ das mulheres e $28 \%$ dos homens tinham 9 anos ou mais de estudo[4].

A partir da década de 60, na Europa Ocidental, espalham-se os supermercados e o mercado da alimentação passa a ser de consumo de massa, possibilitando a otimização da aquisição de alimentos, diminuindo atividades de subsistência e ampliando o mercado de alimentos produzidos industrialmente, com deslocamento progressivo do serviço das cozinhas para as fábricas. Nota- se que, de forma sistemática, cada vez menos, a alimentação se identifica com o universo doméstico ${ }^{[1,2]}$.

Para acesso aos alimentos, em economias mercantis, é preciso dispor de recursos financeiros e tempo, considerando a necessidade de preparar a maioria dos produtos para o consumo no domićlio. Nas

\footnotetext{
${ }^{1}$ Discente do Programa Ciência e Tecnologia de Alimentos - ESALQ/USP. Rua Eliza Pessuti Ribeiro, 178, CEP: 18190-000, Araçoiaba da Serra, SP, (15) 32812892 ou (11) 83593379.E-mail: daniele_leal@hotmail.com
} 
sociedades mais ricas, as atividades de lazer concorrem com as demais atividades, principalmente as domésticas. Este tempo restrito, torna-se um fator determinante nas escolhas dos consumidores, que tem manifestado a preferência por produtos prontos ou semi- prontos para consumo [2].

Durante a história da alimentação humana, esteve presente a necessidade de aumentar a produção e a disponibilidade dos alimentos. Hoje os alimentos estão disponíveis em maior volume e para as pessoas que têm acesso, surgiu um novo desafio ou ainda dificuldades, representadas pela escolha dos alimentos, gerenciamento de sua diversidade e das informações sobre se é saudável, se deve ou não ser consumido, a quantidade adequada , freqüência, entre outros aspectos. $\mathrm{Na}$ comercialização dos alimentos, em restaurantes e hipermercados, há uma ampla oferta de produtos, marcas, lançamentos, serviços e os consumidores têm dificuldade para selecionar criteriosamente os produtos a serem adquiridos.

De acordo com Barreto e Cyrillo[5] , os hábitos alimentares são definidos por variáveis biológicas, demográficas, econômicas, entre outras, que sofrem constantes transformações com o tempo, promovendo a formação de novos padrões dietéticos.

Nas três últimas décadas houve mudanças nos padrões alimentares e um exemplo é a substituição crescente, observada nas sete regiões geográficas do Brasil, de proteína vegetal por animal e de carboidratos por lipídios, indicando elevação no risco de doenças crônico- degenerativas. Outra mudança ocorrida, identificada por meio da Pesquisa de Orçamento Familiar 2002 - 2003[6], foi a diversificação na alimentação da população, com a redução do consumo de alimentos tradicionais como arroz, feijão, batata, pão e açúcar e o crescimento da aquisição de iogurtes, refrigerantes e água mineral. O consumo de alimentos preparados aumentou, de $1,7 \mathrm{~kg} / \mathrm{pessoa} /$ ano para $5,4 \mathrm{~kg}\left[{ }^{[5]}\right.$.

Entre as intensas mudanças ocorridas nos hábitos alimentares da população, tem se destacado o crescimento da frequência da alimentação fora do domicílio, que é condicionada por diversos fatores, como tipos de serviços oferecidos, despesa com alimentação, qualidade do serviço, segurança alimentar e consequente aumento da oferta desse tipo de serviço. A importância do tema motivou a análise apresentada no presente artigo.

\section{Principais serviços de alimentação}

O food service é o termo utilizado para refeições preparadas fora do lar e que abrange as refeições realizadas nos locais de trabalho, lazer, em hotéis e hospitais, refeições (adquiridas pelos consumidores) consumidas no domicilio, porém preparadas em outro local. Este segmento abrange desde cozinhas industriais, redes de fast food, empresas de catering, bares, restaurantes e similares, escolas, sorveterias e padarias até vendedores ambulantes [] .

O restaurante é uma das instituições alimentares mais difundidas no mundo. Esse tipo de comércio surgiu com os mercados e feiras que obrigavam artesões e camponeses a permanecerem fora de seus domicilios por um maior período e, portanto, tendo que se alimentar, estabelecendo-se assim relações sociais, de amizade ou de negócios [1].

A “americanização" trouxe para o Brasil hábitos alimentares em sintonia com o tempo produtivista internacional, exigido pela reprodução capitalista mundial[8].

Alimentar-se fora de casa, de forma rápida, excluindo o arroz e o feijão, há algum tempo, era inconcebível para expressiva parcela da população brasileira. Hoje, com a presença do serviço fast food, o qual o maior representante é a rede do MCDonald's, a realidade das grandes cidades brasileiras foi alterada. É crescente a oferta deste tipo de serviço, onde prevalece a alta rotatividade, o produto é disponibilizado de forma rápida e o serviço classificado pelos consumidores como eficiente. O serviço de fast food amplia-se devido o cotidiano dos grandes centros urbanos, onde prevalece a velocidade no ritmo de vida, fazendo com que as pessoas procurem por serviços rápidos ${ }^{[8]}$.

O expressivo consumo de alimentos em serviços de fast food (principalmente em redes de lanchonetes) e de refrigerantes está relacionado com o crescimento no consumo de gorduras e açúcar e todas as suas consequências nocivas, como o sobrepeso, a obesidade e doenças crônico-degenerativas que são as principais causas de morte em muitos países [?].

No serviço self service, o restaurante oferece opções de guarnição, carne, pratos base (arroz e feijão), saladas, sobremesas, que variam conforme o local em quantidade e variedade e os consumidores se servem em balcões de distribuição do alimento. Pode ser "por quilo", quando a pessoa, após se servir pesa a quantidade de comida e paga um valor proporcional ou come-se à 
vontade e o valor é fixo. Com este serviço, o estabelecimento economiza com mão-de-obra (menor número de garçons) e o serviço é considerado, pelo cliente, como mais rápido.

Consumidores consideraram que entre as principais razões para a escolha de restaurantes com o serviço self service, estão o preço e a praticidade, pois é uma forma rápida, por exemplo, de almoçar e ainda dispor de variedade de alimentos [10].

O "prato feito" é comercializado por estabelecimentos comerciais, e normalmente é composto por arroz, feijão, um tipo de carne, salada e batata frita (geralmente é servido em embalagens tipo "marmitex"), servido em estabelecimentos utilizados, com grande freqüência,por integrantes das classes sociais média e baixa.

Nos serviços de mesa, os clientes são atendidos e servidos após serem acomodados nas mesmas. $\mathrm{O}$ serviço é geralmente à la carte (a maneira do cardápio) e pode ser à americana, à francesa, ou à inglesa.

As cozinhas de rua existiram no mundo inteiro e em todas as épocas e ainda estão presentes em diversas localidades. Por valores baixos serve-se rapidamente um prato feito, lanche ou alimentos pré-cozidos. Essas cozinhas sempre estiveram presentes na China e em toda a Ásia, e também são atuantes na America Latina e no Oriente Médio, porém desapareceram quase completamente na Europa ${ }^{[1]}$.

\section{Serviços de alimentação em instituições e empresas}

\section{Programa de alimentação do trabalhador}

O Ministério do Trabalho e Emprego criou, em 1976, o Programa de Alimentação do Trabalhador (PAT), que registra entre os seus objetivos a melhoria das condições nutricionais dos trabalhadores, por meio de cesta básica, auto-gestão ou terceirização do serviço de alimentação, refeição transportada e convênio refeição ou alimentação (atendendo 48\% dos trabalhadores amparados pelo PAT) ${ }^{[11]}$.

De acordo com dados do Ministério do Trabalho e do Emprego - MTE [12], em abril de 2009, estavam cadastrados no PAT 109529 empresas beneficiárias, 5949 fornecedoras, 11505770 trabalhadores beneficiados (destes 9118592 recebem até 5 salários mínimos e 2387178, recebem acima de 5 salários mínimos), 127 prestadoras de serviço e 8020 nutricionistas.
Bandoni e Jaime ${ }^{[13]}$ avaliaram a qualidade global das refeições servidas em 72 empresas cadastradas no PAT, na cidade de São Paulo, e observaram que estas não estavam adequadas, segundo o Índice de Qualidade da Refeição (IQR). Cabe registrar que o IQR propõe 5 variáveis para avaliar a qualidade da refeição: a adequação na oferta de verduras, legumes e frutas em gramas/refeição; percentual da oferta de carboidratos e gordura total em relação ao total de calorias e de oferta percentual de gordura saturada em relação à energia proveniente dos ácidos graxos saturados e variabilidade da refeição considerando o número e grupo de alimentos [13]. Os autores verificaram também que empresas de menor porte e estrutura tiveram refeições de pior qualidade, quando comparadas com as demais empresas.

São escassos os estudos que avaliem o Programa de Alimentação do Trabalhador e esforços no sentido de preencher tal lacuna devem ser empreendidos pelos pesquisadores da área. Tais resultados seguramente serão reconhecidos como subsídios para a devida reformulação do Programa.

\section{Alimentação escolar}

O Programa Nacional de Alimentação EscolarPNAE, que tem como objetivo o atendimento das necessidades nutricionais dos alunos da educação infantil e do ensino fundamental, durante sua permanência em sala de aula, atendeu no ano de 2008, 34,6 milhões de alunos com recursos financeiros de $\mathrm{R} \$ 1.490$ milhões ${ }^{[14]}$.

Tendo em vista que expressiva parcela de alunos da rede de escolas públicas e particulares consome alimentos servidos gratuitamente, por meio do PNAE, ou comercializados pelas cantinas estabelecidas nas unidades de ensino é necessário considerar alguns atributos desses alimentos, especialmente aqueles comercializados em cantinas. Frequentemente esses alimentos revelam elevada densidade energética e, portanto, é notória a necessidade de orientar os alunos para a seleção adequada dos alimentos que deverão ser consumidos. As cantinas também podem influir diretamente na menor adesão dos alunos ao Programa de Alimentação Escolar, que distribui refeições gratuitas e que tem como meta o equilíbrio nutricional das preparações ${ }^{[15]}$.

No caso de cantinas ou similares, como bares e lanchonetes, não estiverem de acordo com os princípios de uma alimentação saudável, os conhecimentos adquiridos por alunos, especialmente por meio das atividades educativas da escola, a esse respeito serão 
ignorados ou esquecidos durante o processo das escolhas alimentares [15].

Mais recentemente foram instituídas as diretrizes para a alimentação saudável nas escolas públicas e particulares do Brasil, com o reconhecimento que esta deve ser entendida como um direito humano e adequada às necessidades sociais, biológicas e culturais dos indivíduos ${ }^{[16]}$.

A promoção da alimentação saudável nas escolas deve ter como base alguns princípios, como por exemplos as ações de educação alimentar e nutricional, estímulo à produção de hortas escolares e restrição do comércio de alimentos e preparações com altos teores de gordura saturada, gordura trans, açúcar livre e sal, além do monitoramento do estado nutricional dos escolares. Os serviços de alimentação devem ser concordantes com as boas práticas de manipulação ${ }^{[16]}$.

No tocante ao preparo das refeições, pesquisa visando a avaliação das condições higiênico-sanitárias em 24 unidades de preparação da alimentação escolar da rede estadual da cidade de São Paulo revelou que os locais de preparo e distribuição, equipamentos e utensílios não se encontravam em conformidade ${ }^{[17]}$ com os parâmetros preconizados pela legislação. Piragina [18] observou que com a capacitação dos funcionários e merendeiras é possível atingir uma melhora nos serviços oferecidos.

Pesquisa de Ravagnani e Sturion [19] com o objetivo de avaliar o nível de adequação às Boas Práticas em Unidades de Alimentação e Nutrição (UAN) de centros educacionais infantis (CEI) municipais de Piracicaba (SP) revelou nível insatisfatório $(64,3 \%)$ de adequação às Boas Práticas. Dos itens não conformes, aproximadamente $45 \%$ evidenciaram a necessidade de adoção de medidas corretivas imediatas. As análises microbiológicas atestaram as deficiências no processo.

No que diz respeito à comercialização de alimentos para a população adulta a avaliação microbiológica em 80 salgados coletados em lanchonetes instaladas em centros universitários, na cidade de Piracicaba (SP) revelou problemas higiênico- sanitários na produção e conservação dos alimentos. Tal situação, de acordo com os autores pode, com grande probabilidade, expor a riscos a saúde dos consumidores [20].

\section{Restaurantes populares}

Os restaurantes populares são destinados ao preparo e comercialização de refeições saudáveis, oferecidas a preços acessíveis a grupos populacionais formados por trabalhadores formais e informais de baixa renda, desempregados, estudantes, aposentados, moradores de rua e famílias em situação de risco de insegurança alimentar e nutricional. Os restaurantes são localizados, preferencialmente, em grandes centros urbanos de cidades com mais de 100 mil habitantes [21].

Um convênio entre o Governo do Estado de São Paulo com entidades comunitárias e assistenciais da sociedade civil, sem fins lucrativos e a administração da Secretaria de Agricultura e Abastecimento criou 30 unidades do restaurante Bom Prato, que fornecem até 42.320 refeições subsidiadas por dia (o custo de cada refeição é de $\mathrm{R} \$ 3,25)$. O Governo do Estado subsidiava $\mathrm{R} \$ 2,25$ e o custo (final) para o usuário era de $\mathrm{R} \$ 1,00$. O objetivo deste projeto é a promoção do acesso à segurança alimentar e nutricional à população de baixa renda, oferecendo refeições balanceadas [22].

\section{Despesas com alimentação}

$\mathrm{Na}$ década de 60, os franceses gastavam, em média, 30\% de sua renda com alimentação. Em meados da primeira década do século XXI destinam $20 \%$, sendo $15 \%$ para alimentação no domicílio e $5 \%$ fora dele ${ }^{[2]}$.

A Pesquisa de Orçamentos Familiares (POF) implementada entre outubro de 1995 a setembro de 1996 analisou a proporção da despesa média mensal familiar, com os gastos com a alimentação. Foi avaliado, que dentre as despesas domiciliares, a alimentação representou em média 16,39\% dos gastos, em famílias que recebiam de 2 a 3 salários mínimos (com valor de $\mathrm{R} \$ 112,00$ na época) e a alimentação representou 33,94\% (maior valor encontrado) das despesas [23].

Os dados mostraram ainda que da totalidade da despesa com alimentação (100\%), 74,55\% era destinada para alimentação no domicílio, destes 2,27\% com alimentos comprados prontos para consumo e 25, $45 \%$ com alimentação fora do domicílio. Deste valor, 13,05\% com almoço e jantar, $0,49 \%$ com café, leite, café com leite e chocolate, 3,83\% com sanduíches e salgados, $5,20 \%$ com refrigerantes, cervejas e outros e $2,88 \%$ com agregadas [23]. Por classe de rendimento mensal, o grupo com rendimento de 20 a 30 salários foi o que destinou a maior parcela $(36,25 \%)$ de suas despesas com alimentação fora do domicilio. Em situação oposta menor parte $(11,84 \%)$ da despesa com alimentação fora de casa - foram identificados os integrantes das classes com recebimento mensal de 2 a 3 salários mínimos.

De acordo com a Pesquisa de Orçamentos Familiares - POF, realizada entre os anos de 2002 e 2003, em relação às despesas de consumo no Brasil 
(alimentação, habitação, transporte, assistência à saúde, educação, recreação e cultura, vestuário, higiene e cuidados pessoais, fumo, serviços pessoais, despesas diversas e outras despesas correntes), a proporção destinada à alimentação situou-se no intervalo de $19 \%$ a $23 \%[6]$.

Em todas as avaliações sobre a quantidade de alimentos consumidos, a população rural adquiriu uma quantidade total de alimentos $30,5 \%$ a mais que a população urbana. Um motivo considerado plausível é o restrito acesso à alimentação fora de casa, devido aos hábitos familiares e o rarefeito número de estabelecimentos voltados para esta finalidade [ $[$.

Os gastos com alimentação no domicílio equivaleram a $75,95 \%$ dos gastos com alimentos e fora do domicílio, 24,05\%, valores próximos aos encontrados na pesquisa anterior (1995- 1996). O percentual gasto com alimentação fora do domicílio na área urbana alcançou 25,74\%- valor que supera o encontrado $(13,07 \%)$ para os moradores da área rural. Entre as regiões brasileiras, destaca-se o Sudeste onde a população mais gastou $(26,91 \%)$ com alimentação fora do domicílio e as menores proporções verificadas são nas regiões Nordeste $(19,52 \%)$ e Norte $(19,10 \%)$. Cabe destacar que nas regiões Norte e Nordeste são os setores onde mais se gastou com bebidas alcoólicas fora do domicilio $(5,82 \% \mathrm{e}$ $6,84 \%$ respectivamente) [24].

Comparando as classes sociais, por meio dos rendimentos, foi possível observar que o grupamento com os menores valores (até $\mathrm{R} \$ 400,00$ ) gastou em média $\mathrm{R} \$ 148,59$ com alimentação $(88,19 \%$ no domicílio e $11,81 \%$ fora dele) e as classes relativamente mais ricas (acima de $\mathrm{R} \$ 4.000,00$ ), revelou despesa média de $\mathrm{R} \$$ 662,72 com alimentação (62,95\% no domicílio e 37,05\% fora dele) [24].

Uma pesquisa divulgada pela Associação das Empresas de Refeição e Alimentação Convênio para o Trabalhador - ASSERT, realizada em 2252 restaurantes em 22 cidades do Brasil que aceitavam tíquete e valerefeição, mostrou que o trabalhador recebia vale de $\mathrm{R} \$$ 10, em média, e que as refeições completas tinham valores médios de R \$16,00 [25, 26]. Em 2007 o gasto médio (almoços) era em torno de $\mathrm{R} \$ 14,87$. Uma região onde a comida foi considerada de alto custo é o centro oeste, uma das maiores produtoras de carne e grãos do país. É apresentada a justificativa do valor pago pelo frete dos alimentos (oriundos de outras regiões até a região centro- oeste) para o valor médio das refeições alcançarem $\mathrm{R} \$ 17,58$. Na região Sul, o preço médio de $\mathrm{R} \$$ 13,88 foi considerado "mais barato" e a justificativa apresentada para tal valor praticado pelos estabelecimentos foi a concorrência ${ }^{[25,26]}$.

\section{Freqüência da alimentação fora do domicílio}

Na pesquisa de Pineyura [10], envolvendo 1545 consumidores das cidades de São Paulo, Recife, Goiânia e Porto Alegre foi observado, tendo por base informações fornecidas pelos entrevistados, que $\mathrm{O}$ consumo alimentar rotineiro é determinado, predominantemente, pela vida profissional e pela composição de hábitos familiares.

O café da manhã e o jantar são, em geral, consumidos em casa e aproximadamente metade do público investigado almoçava fora de casa durante a semana, na própria empresa ou em restaurantes próximos à empresa, geralmente, optando pelo self service (por quilo). $\mathrm{Na}$ escolha dos pratos nos finais de semana, considerando que poucos cozinhavam em casa durante a semana, predominava a opção por preparações fáceis, para não "perder tempo" no preparo das refeições ${ }^{[10] .}$

Pesquisa que envolveu 250 pessoas, residentes na cidade de Campinas (SP) que costumavam se alimentar fora de casa mostrou o grau de importância dos fatores que influenciavam na escolha dos estabelecimentos pelos consumidores. Foi considerado como o fator mais importante a higiene dos funcionários, seguida pela higiene do local e a qualidade dos alimentos oferecidos ${ }^{[26]}$.

Trabalho de Sanches[27] mostrou que 98\% dos consumidores pesquisados costumavam almoçar fora de casa (38,8\% de 4 a 7 vezes por semana e $28,8 \%$ de 1 a 3 vezes geralmente em restaurante self service). A segunda refeição realizada com maior frequência fora de casa foi o lanche da tarde $(17,6 \%$ dos consumidores - de 4 a 7 vezes por semana).

Adolescentes e adultos nos Estados Unidos, que se alimentavam, frequentemente em restaurantes fast food, foram questionados sobre as motivações para a escolha desses serviços e revelaram as seguintes razões: comida rápida $(92 \%)$, restaurantes de fácil acesso $(80 \%)$ e sabor bom $(69 \%)$. As razões menos registradas foram: "que é um meio de se socializar com família e amigos" (33\%) e alimentos nutritivos $(21 \%)^{[28]}$.

\section{Segurança alimentar nos serviços de alimentação}

Por meio de estudo que visou avaliar a influência do contexto do local, onde se dá o consumo, sobre a percepção da qualidade do alimento preparado foi 
verificado que, quanto mais requintado o ambiente, maior será a avaliação de qualidade do alimento e que esta é influenciada pelo design do local e maior preço. $\mathrm{O}$ atendimento e aspecto dos funcionários não foram relacionados à qualidade do alimento [29].

Em 10 Unidades Produtoras de Refeição (UPR), foram avaliadas atitudes de risco de contaminação, tendo por amostra 3447 consumidores que utilizavam o balcão de distribuição. As atitudes de risco mais presentes foram: conversas dos clientes em cima das preparações oferecidas no balcão de distribuição enquanto escolhiam os alimentos, o uso do utensílio de uma preparação em outra já servida no prato, não higienização das mãos antes de se servir, utilizar utensílios para arrumar os alimentos no prato [30]. $\mathrm{Na} \mathrm{UPR}$, onde havia vidro de proteção no balcão de distribuição foi verificada diminuição do risco causado por consumidores que conversavam muito próximos das preparações. O estudo concluiu que a prevenção da contaminação dos alimentos também é tarefa dos consumidores, que devem ser orientados sobre atitudes apropriadas a serem adotadas enquanto se servem [30].

$\mathrm{Na}$ cidade de Ipatinga foi conduzido estudo que avaliou as condições higiênico-sanitárias de 123 restaurantes comerciais. Observou-se precariedade no controle higiênico-sanitário, principalmente nos requisitos para produção de alimentos, no controle de vetores, equipamentos, documentação e registros. Em 20 destes estabelecimentos, o conhecimento dos manipuladores no que tange às Boas Práticas de Manipulação (BPM) era falho e $47,4 \%$ dos manipuladores relataram ter participado de cursos de BPM [31]. A mesma pesquisa mostrou que entre as amostras de alimentos (cadeia de frios e quentes dos restaurantes) apenas $5 \%$ da cadeia de frios foi aprovada e $20 \%$ atendiam a manutenção de temperatura quente. Aproximadamente $75 \%$ das amostras, a base de carne, coletadas da cadeia quente, estava em conformidade com os padrões microbiológicos estabelecidos pela legislação [31].

Pesquisa implementada no Canadá demonstrou que o conhecimento de manipuladores de alimentos sobre o conceito de alimento seguro era maior quando os mesmos recebiam treinamento especifico. Os manipuladores com menor nível de informação eram aqueles que não receberam treinamento e aqueles com menos de um ano ou com mais de dez anos de profissão ${ }^{[32]}$.

Foi averiguada a adoção de sistemas de controle de qualidade e qualificação dos recursos humanos em amostra composta de 18 restaurantes nas cidades de
Campinas (SP) e Porto Alegre (RS), com relação ao sistema de Análise de Perigos e Pontos Críticos de Controle - APPCC e as normas das Boas Práticas de Fabricação-BPF. Os resultados mostraram que 56\% dos entrevistados afirmam desconhecer, 11\% afirmaram que estavam iniciando processo de implantação, $11 \%$ adotaram as $\mathrm{BPF}$ e $22 \%$ afirmaram conhecer, mas não adotavam. A pesquisa mostrou que cursos e treinamentos foram oferecidos em $56 \%$ dos restaurantes ${ }^{[3]}$.

Em revisão bibliográfica sobre a efetividade das intervenções em serviços de alimentação, com vistas à adequação para a segurança de alimentos, foram considerados os seguintes fatores: importância da inspeção no serviço de alimentação pelo menos uma vez por ano para reduzir o risco de doenças transmitidas por alimentos, treinamento de manipuladores para aumentar os conhecimentos e práticas em manipulação e programas de educação para a sociedade ampliar seu conhecimento sobre alimentos seguros [34].

Uma pesquisa implementada no município de Campinas identificou a falta de conhecimento e informação, por parte de proprietários de estabelecimentos comerciais de pequeno porte, em relação ao cumprimento das normas e regulamentos exigidos para a comercialização de alimentos. Além disso, foi observado relativo descrédito por parte dos referidos proprietários em relação à atuação fiscalizatória e punitiva dos órgãos públicos de proteção do consumidor [35].

\section{Comércio de alimentos na rua}

A Food and Agriculture Organization of the United Nations - FAO [36] considera o comércio de alimentos na rua uma importante contribuição para geração de empregos, renda familiar, principalmente em países em desenvolvimento. Este setor "informal" de alimentos frequentemente não é submetido à fiscalização e controle de qualidade, podendo causar problemas, comprometendo a segurança de alimentos e ainda contribuir para a deterioração do meio ambiente.

Considerando que alimentos de rua podem representar uma ameaça à saúde do consumidor, Lucca e Torres [37] avaliaram as condições de higiene de "cachorros-quentes" comercializados em vias públicas, em 20 pontos de venda. Os autores verificaram que 30\% dos estabelecimentos revelavam condições regulares ou péssimas de higiene e as preparações a base de carne, purê e frango foram consideradas de alto risco.

A qualidade microbiológica de "cachorros quentes" e hambúrgueres em oito pontos de comércio 
ambulante foi avaliada no município de Juazeiro do Norte (Ceará). Os hambúrgueres apresentaram resultados negativos para presença de coliformes, mofos e leveduras. As amostras de carne moída, que integravam a preparação dos "cachorros quentes" apresentaram 25\% de contaminação por coliformes totais e coliformes termotolerantes. Os autores concluíram que não existe estrutura básica aceitável para este tipo de comércio na cidade de Juazeiro do Norte, sendo ausente também a fiscalização séria no comércio de comida de rua. As técnicas de manipulação foram consideradas inadequadas e os manipuladores não tinham conhecimentos básicos sobre segurança alimentar e higiene ${ }^{[38]}$.

Devem ser adotadas algumas medidas para melhorar a qualidade de alimentos comercializados na rua, como exemplo o desenvolvimento e aplicação de normas sanitárias adequadas a esse tipo de comércio, implementação de cursos de capacitação aos vendedores, estabelecimento de um sistema de vigilância sanitária e informação epidemiológica de doenças veiculadas por alimentos comercializados em vias públicas e adoção de medidas governamentais que visem a regularização, concessão de licenças e mecanismos de controle de atividade [39].

\section{Segurança nutricional nos serviços de alimentação}

A mensuração da atitude de 250 consumidores frente à informação nutricional dos alimentos comercializados em restaurantes revelou que, 78\% dos entrevistados "concordaram muito" sobre a importância da disponibilização da referida informação para os consumidores que necessitam de uma dieta específica e $28 \%$ informaram ter tido acesso às informações nutricionais em restaurantes que frequentaram. Investimentos neste tipo de ação podem ser benéficos para os consumidores e para o setor privado. A autora enfatiza que quanto maior o conhecimento nutricional do consumidor, mais positiva será sua atitude em relação à informação nutricional dos alimentos oferecidos nos restaurantes [27].

Pesquisa envolvendo consumidores americanos mostrou que os mesmos reconheceram a importância da informação nutricional referente às porções comercializadas por restaurantes "de serviço rápido". Contudo, os consumidores informaram que não utilizavam habitualmente as informações e consideravam que deveriam ser priorizadas as informações relativas às calorias. Os consumidores enfatizaram a importância da disponibilidade de recomendações e sugestões sobre escolhas mais saudáveis ${ }^{[40]}$.
Maestro [41] implementou pesquisa envolvendo amostra formada por 20 gerentes de restaurantes fast food e 94, de restaurantes full service. Do total da amostra, $25,4 \%$ dos restaurantes (fast food), utilizam informação nutricional e/ou de saúde, principalmente por meio da declaração de nutrientes, como valor energético e de macronutrientes.

\section{Considerações sobre os serviços de alimentação}

A National Restaurant Association [42] elaborou projeção da indústria de restaurantes nos Estados Unidos em 2009, com vendas de $\$ 566$ bilhões de dólares (no ano de 2000, foi de $\$ 379$ bilhões), 945.000 estabelecimentos e 13 milhões de empregos no setor. A estimativa de venda em bilhões é de $\$ 516 \mathrm{em}$ restaurantes comerciais (comércio de bebida, comida, restaurantes de hotel), \$ 52,9 em comércio de rua e $\$ 49,0$ em outros tipos de serviços de alimentação. A estimativa de crescimento das vendas na indústria de restaurante é de 2,5\% e em um dia típico de 2009, 1,5 bilhões de dólares em vendas diárias.

Nos Estados Unidos, $76 \%$ dos adultos estavam tentando se alimentar de forma mais saudável, na época da pesquisa, quando utilizavam os serviços dos restaurantes. Proporção expressiva $(70 \%)$ de adultos preferiu restaurantes que utilizavam alimentos produzidos na própria região. Proporção(27\%) dos adultos revelou que estava mais preocupado com os valores das refeições comercializadas pelos restaurantes do que nos dois anos anteriores da pesquisa. É destacado também que a participação da indústria dos restaurantes no setor alimentício era de $25 \%$ em 1955 e alcançou $48 \%$ [ ${ }^{[42]}$.

O serviço de alimentação, segmento que compreende restaurantes, bares, padarias, lojas de conveniência, fast food, cresce a uma taxa anual acima de $10 \%$ e adquire $25 \%$ da produção da indústria alimentícia brasileira, conta com mais de 1,2 milhão de pontos de venda e em 2005 faturou $\mathrm{R} \$ 38,1$ bilhões [43]. A estimativa é que nos grandes centros urbanos, o número de refeições fora do lar chegue a 30\% das refeições totais [7].

Segundo dados da Associação Brasileira de Refeições Coletivas - ABERC [44], no ano de 2009 o referido segmento movimentou 28,7 bilhões de reais, gerou 180 mil empregos diretos e serviu 13,68 milhões de refeições/dia, incluindo serviço de autogestão (refeições produzidas pela própria empresa), terceirização do serviço e refeições convênio (tíquetes e cupons para restaurantes comerciais).

De acordo com a Associação brasileira de bares e restaurantes [25], houve no primeiro trimestre de 2009, 
$5 \%$ de aumento real no faturamento do setor de bares e restaurantes em comparação com o mesmo período em 2008. Em restaurantes de áreas turísticas, esse crescimento chegou a $12 \%$.

Reportagem no jornal O Estado de São Paulo registrou que, em meio à pior crise mundial nos últimos 60 anos, responsáveis pelas lanchonetes de fast food afirmaram lucrar, enquanto outras pesquisas mostram que cada vez mais americanos e europeus estavam trocando restaurantes por refeições mais baratas, encontradas, especialmente, em redes de fast food. A câmara de vereadores de uma cidade italiana,visando o estimulo para o consumo de comidas do país, proibiu, em meio à crise financeira, a abertura de lanchonetes $\mathrm{e}$ restaurantes de comidas turcas, árabes e chinesas [45].

\section{Considerações finais}

É notável o crescimento da frequência e do hábito das pessoas se alimentarem fora do domicílio. Tais alterações são decorrentes das constantes mudanças profissionais, culturais, econômicas, entre outras. Em consequência tem- se a quantidade e variedade na oferta dos serviços de alimentação, que estão aumentando e a qualidade passando por diversificação, pois alguns gerentes de estabelecimentos, se preocupam com a qualidade sanitária e nutricional e outros ainda, de forma imprópria, não valorizam tais características. Com grande frequência, os referidos gerentes não detem conhecimento e em muitos casos os estabelecimentos não possuem estrutura e pior, esses locais não são rotineiramente fiscalizados pelos órgãos responsáveis.

É crescente a preocupação da população com atributos de qualidade do alimento e dos serviços de alimentação, porém a maioria destes consumidores não possui informações suficientes para avaliar e reivindicar melhorias. É necessária a formulação de políticas públicas permanentes, com vistas à promoção da educação da população para escolhas que priorizem os alimentos nutricionalmente mais saudáveis e também para a opção por estabelecimentos que apresentem condições higiênico-sanitárias adequadas.

Parece prevalecer que a principal refeição feita fora do domicílio é o almoço e os serviços mais procurados são os rápidos e práticos, como self service e fast food.

A qualidade dos serviços de alimentação, oferecidos para trabalhadores e estudantes, é essencial para que os mesmos tenham acesso à segurança alimentar e nutricional.
O mercado que supre a demanda por alimentação fora do domicílio, tem uma participação significativa e crescente no setor alimentício e na geração de empregos diretos e indiretos, principalmente nos grandes centros urbanos e, portanto, demanda atenção redobrada dos diversos segmentos da sociedade.

\section{Referências Bibliográficas}

1. Flandrin JL, Montanari M. História da alimentação. São Paulo: Estação Liberdade, 1998.

2. Lambert JL, Batalha MO, Sproesser RL, Silva AL, Lucchese T. As principais evoluções dos comportamentos alimentares: o caso da França. Revista de Nutrição. 2005; May/jun; 18(5):577-91.

3. Fundação Carlos Chagas. Mulheres no Mercado de Trabalho: Grandes Números. [citado 2009 abr 22]. Disponível em: http://www.fcc.org.br/mulher/series_historicas/mmt.h tml.

4. Fundação Carlos Chagas. Mulheres brasileiras, Educação e Trabalho. [citado 2009 abr 22]. Disponível em:

http://www.fcc.org.br/mulher/series historicas/mbet. html.

5. Barretos SAJ, Cyrillo DC. Análise da composição dos gastos com alimentação no município de São Paulo (Brasil) na década de 1990. Revista de Saúde Pública. 2001; 35( 1): 52-9.

6. Brasil. Ministério do Planejamento, orçamento e gestão - IBGE. Diretoria de Pesquisas, coordenação de trabalho e rendimento. Pesquisa de Orçamentos Familiares (POF) 2002-2003. [citado 2009 abr. 01]. Disponível em: http://www.ibge.gov.br/home/estatistica/populacao/c ondicaodevida/pof/2002_2003perfil/pof2002_2003pe rfil.pdf.

7. Silva Junior JH. Food service: serviço requer profissionais do futuro. Food Service News [periódico eletrônico]. 2005 jul; [citado 2009 abr 22]. Disponível em:

http://www.foodservicenews.com.br/artigos.php?id= 6 .

8. Alves CLR. O evangelho Segundo o McDonald's: um estudo sobre o processo de produção da fast food. [dissertação]. São Paulo: Pontifícia Universidade Católica, 2006. 157 p.

9. Granados JAT. Fast Food Nation: the dark side of the all-american meal. Revista Panamericana de Salud Pública. 2002 ago; 12(2) [citado 2009 abr 10]. 
Disponível http://www.scielosp.org/pdf/rpsp/v12n2/11625.pdf.

10. Pineyura DGF. Regionalismo alimentar: identificação de grupos de consumidores que valorizam o prazer e as tradições alimentares. [dissertação]. Campo Grande: Universidade Federal de Mato Grosso do Sul; 2006. $117 \mathrm{p}$.

11. Ferrari J. O almoço cabe no Bolso? Food Service News. [ citado 2009 abr 22 ]. Disponível em: http://www.foodservicenews.com.br/materia.php?id= 24 .

12. Ministério do trabalho e emprego. Inspeção do Trabalho: Programa de Alimentação ao Trabalhador PAT. [citado 2009 abr 24]. Disponível em: http://www.mte.gov.br/pat/relatorios_apartir_2008.as $\mathrm{p}$.

13. Bandoni DH, Jaime PC. A qualidade das refeições de empresas cadastradas no Programa de Alimentação do Trabalhador na cidade de São Paulo. Revista de Nutrição. Mar/ Abr 2008;21(2). [citado 2009 abr 11] Disponível http://www.scielo.br/scielo.php?pid=S141552732008000200006\&script=sci_arttext.

14. Fundo nacional de desenvolvimento da educação. Alimentação Escolar [citado 2009 abr 27]. Disponível em

http://www.fnde.gov.br/home/index.jsp?arquivo=ali mentacao_escolar.html\#dadosesta.

15. Danelon MAS, Danelon MS, Silva MV. Serviços de alimentação destinados ao público escolar: análise da convivência do Programa de Alimentação Escolar e das cantinas. Segurança Alimentar e Nutricional. 2006; 13(1):85 - 94 .

16. Brasil. Ministério da saúde, Ministério da educação. Institui as diretrizes para a promoção da alimentação saudável nas escolas de educação infantil, fundamental e nível médio das redes públicas e privadas, em âmbito nacional. Portaria Interministerial n ${ }^{\circ} 1.010$ de 8 de maio de 2006 .

17. Silva C, Germano MIS, Germano PML. Condições higiênico - sanitárias dos locais e preparação da merenda escolar, da rede estadual de ensino em São Paulo, SP. Higiene Alimentar. 2003; jul;17(110): 49 55.

18. Piragina KO. Aspectos higiênicos e sanitários do preparo da merenda escolar na rede estadual de ensino de Curitiba [dissertação]. Curitiba: Programa de Pósgraduação em Tecnologia de Alimentos da Universidade Federal do Paraná; 2005. 107p.
19. Ravagnani EM, Sturion GL. Avaliação da viabilidade de implementação das boas práticas em Unidades de Alimentação e Nutrição de Centros de Educação Infantil de Piracicaba, São Paulo. Segurança Alimentar e Nutricional. 2009; 16(2): 43-59.

20. Nascimento GGF, Romero CEM, Campos MSP, Souza RL, Calçada MLM. Avaliação microbiológica de alimentos comercializados em lanchonetes de campi universitários. Higiene Alimentar. 2003 jul;(17)110: 8589.

21. Ministério do desenvolvimento social e combate à fome. Restaurantes Populares. [citado 2009 set. 29] Disponível http://www.mds.gov.br/programas/segurancaalimentar-e-nutricional-san/restaurante-popular.

22. Governo de São Paulo. Secretaria de agricultura e abastecimento. Projeto de Restaurantes Populares Bom Prato [citado 2009 abr 24]. Disponível em: http://www.codeagro.sp.gov.br/bom_prato/bom_prat o.php?pg=2 .

23. Brasil. Ministério do Planejamento, orçamento e gestão - IBGE. Pesquisa de Orçamentos Familiares - POF 1995 - 1996. Publicação completa. [citado 2009 abr 01 ] Disponível em: $\mathrm{ftp}: / / \mathrm{ftp}$. ibge.gov.br/Orcamentos_Familiares.

24. Brasil. Ministério do planejamento, orçamento e gestão - IBGE . Em 30 anos, importantes mudanças nos hábitos de consumo dos brasileiros. [citado 2009 de abr 01] Disponível em: http://www.ibge.gov.br/home/presidencia/noticias/no ticia_visualiza.php?id_noticia $=171 \& i d$ _pagina $=1$.

25. Associação brasileira de bares e restaurantes ABRASEL. Brasileiro gasta em media R\$ 16 no almoço, diz pesquisa [citado 2009 abr 22]. Disponível em:

http://www.abrasel.com.br/index.php/atualidade/item /5477/.

26. Trabalhadores têm muitos gastos com refeição. Jornal hoje. 2009 abr; [citado 2009 abr 22]. Disponível em: http://g1.globo.com/jornalhoje/0,„MUL1084736-16022,00TRABALHADORES+TEM+MUITOS+GASTOS+COM+ REFEICOES.html

27. Sanches M. Alimentação fora do domicílio: a atitude do consumidor frente à informação nutricional dos alimentos disponibilizada por restaurantes, Campinas SP. [tese] Campinas: Universidade Estadual de Campinas; 2007. 186 p.

28. Rydell SA, Harnack L, Oakes J, Story M, Jeffery R, French S. Why eat fast food restaurants: reported 
reasons among frequent consumers. American Dietetic Association. 2008;108(12):2066-77.

29. Almeida EC. A influência do contexto de consumo sobre a qualidade percebida de alimentos consumidos fora de casa [dissertação]. Campo Grande: Universidade Federal de Mato Grosso do Sul, 2006. 90 p.

30. Zandonadi RP, Botelho RBA, Sávio KEO, Akutsu RC, Araújo WMC. Atitudes de risco do consumidor em restaurantes de auto serviço. Revista de Nutrição. 2007 jan/fev ;20(1):19-26.

31. Badaró ACL. Boas práticas para serviços de alimentação: um estudo em restaurantes comerciais no município de Ipatinga, Minas Gerais [dissertação]. Minas Gerais : Universidade Federal de Viçosa, 2007. $156 \mathrm{p}$.

32. Hislop N, Shaw K. Food Safety Knowledge retention study. Journal of Food Protection. 2009 fev 72 (2): 431-5.

33. Cavalli SB. Segurança do Alimento e recursos humanos: estudo exploratório em restaurantes comerciais dos municípios de Campinas - SP e Porto Alegre - RS. Higiene Alimentar. 2004 nov/dez;18 (126/127):28-35.

34. Campbell ME, Gardner CE, Dwyer JJ, Isaacs SM, Krueger PD, Ying JY. Effectiveness of public health interventions in food safety: a systematic reviw. Can Journal Public Health. 1998 mai/jun;89(3):197-202.

35. Vieira CM, Salay E. Atuação pública municipal de Proteção dos consumidores Frente à questão de segurança de alimentos: o caso do PROCON Campinas. Cadernos de Debate, Núcleo de Estudos e Pesquisas em alimentação da Unicamp.2001; VIII: 15 27.

36. Food and agriculture organization of the United Nations - FAO [citado 2009 abr 08]. Disponível em: http://www.fao.org/ag/agn/agns/foodproducts_street en.asp.
37. Lucca A, Torres EAFS. Condições de higiene de "cachorro-quente" comercializado em vias públicas. Revista de Saúde Pública. 2002;36 (3):350-2.

38. Brito G, Cordeiro L N, Josino SA, Melo ML, Coutinho HDM. Avaliação da qualidade microbiológica de hambúrgueres e cachorros-quentes comercializados por vendedores ambulantes no município de Juazeiro do Norte, CE. Higiene Alimentar. 2003 jul;17(110):90-94.

39. Oliveira G, Nogueira FAG, Zanão CFP, Souza CWO, Spoto MHF. Análise das condições do comércio de caldo de cana em vias públicas de municípios paulistas. Segurança Alimentar e Nutricional. 2006; 13(2):06 .

40. Lando AM, Labiner - Wolfe J. Helping consumers make more healthful food choices: Consumer views on modifying food labels and providing point-ofpurchase nutrition information at quick- service restaurants. Journal of Nutrition Education and behavior. 2007 May/jun ;39(3):157-163.

41. Maestro V. Análise do oferecimento da informação nutricional e de saúde em restaurantes comerciais do município de Campinas/SP [tese]. Campinas : Universidade Estadual de Campinas; 2007. 186 p.

42. National restaurant association. [citado 2009 abr 08] Disponível http://www.restaurant.org/research/ind_glance.cfm.

43. Gouveia F. Indústria de alimentos: no caminho da inovação e de novos produtos. Inovação Uniemp. 2006 nov/dez;2(5) [citado 2009 abril 03]. Disponível em: http:/ /inovacao.scielo.br/scielo.php?script=sci_arttext\&pid= S1808-23942006000500020\&lng $=$ es\&nrm $=$ iso\&tlng $=$ es.

44. Associação brasileira das refeições coletivas. Mercado Real. [citado 2010 ago 26] Disponível em: www.aberc.com.br.

45. Grandes redes de fast food lucram na crise. O Estado de São Paulo. 2009 fev 14. Canal food service, seção negócios: B11. 